\title{
DESIGN AND SIMULATION OF COUPLED-LINE COUPLER WITH DIFFERENT VALUES OF COUPLING EFFICIENCY
}

\author{
${ }^{1}$ SULEIMAN BABANI, ${ }^{2}$ JAZULI SUNUSI KAZAURE, ${ }^{3}$ TONGA AGADI DANLADI, \\ ${ }^{4}$ ABDURRAHMAN LAWAN UMAR \\ ${ }^{1,2,3,4}$ Department of Electrical and Electronics Engineering, Hussaini Adamu Federal Polytechnic, \\ P.M.B 5004 Kazaure, Jigawa State Nigeria \\ E-mail: 'sbabani2000@ gmail.com
}

\begin{abstract}
In this paper, two coupled-line couplers are designed and simulated using stripline technology. The coupled-line couplers (A and B) are designed with different values of coupling coefficient $6 \mathrm{~dB}$ and $10 \mathrm{~dB}$ respectively. Both of circuits have a coupled output port, a through output port and an isolated output port. Moreover, both circuits are tuned to function around $2.45 \mathrm{GHz}$. The design results are presented by simulation results obtained using ADS 2012.08 (Advanced Design System) software.
\end{abstract}

Index Terms-Ads, Coupled-Line Coupler, Directional Coupler, Stripline,

\section{INTRODUCTION}

Directional Couplers are one of the microwave passive components that are used in array antennas, modulators, filters and power amplifiers for propose of dividing or combining the power. A coupled-line coupler (CLC) is one of the configuration directional coupler. As, shown in figure1, CLC is a four-port network constituted by the combination of two unshielded transmission lines (TLs) in close proximity to each other. Due to this proximity, the electromagnetic fields of each line interact with each other, which cause to power trade between the two lines, or coupling.

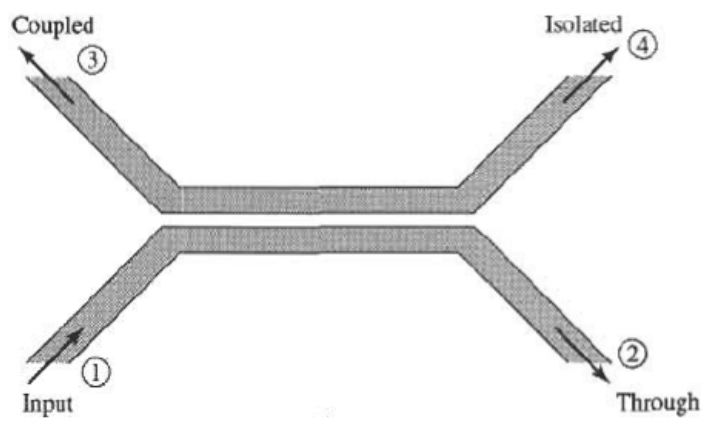

Fig.1. Typical structure of a coupled-line coupler (CLC)

Basically, there are two types of CLC, backward wave and forward wave couplers. When the output coupling port is in the vicinity of the input port, the CLC is named backward as shown in figure 1, otherwise it is forward.

There are two modes of current flow in an electromagnetic situation for a coupled line. The first is one current flowing down one conductor with a contra-flow current back up the other conductor caused by displacement current coupling between the two conductors. This is termed the odd mode current, and it has associated odd mode characteristic impedance, styled Z0o. The other mode is one current flow by displacement current between each Centre conductor carrying the same polarity, and the ground that is common between them. Hence this is called the even mode current, and it has an associated even mode characteristic impedance, styled Z0e. Fig. 2 shows the polarity of the lines of each mode.

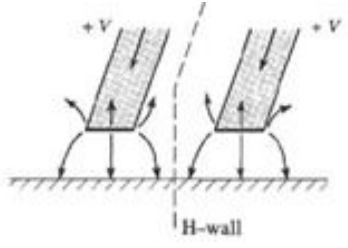

Even mode

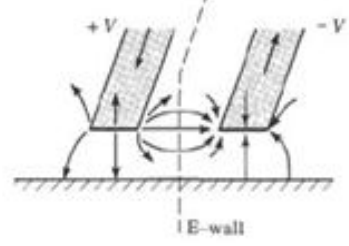

Odd mode
Fig.2. Even and odd modes excitations for a coupled line

For a single section coupler the even and odd mode characteristic impedances are defined as:

$$
\begin{aligned}
& Z_{0 e}=Z_{O} \sqrt{\frac{1+C}{1-C}} \\
& Z_{0 o}=Z_{O} \sqrt{\frac{1-C}{1+C}}
\end{aligned}
$$

Where $\mathrm{Z}_{\mathrm{O}}$ the characteristic impedance, and $\mathrm{C}<1$ is the voltage coupling coefficient of the coupler. In this paper, two backward coupled-line coupler will be designed and simulated using stripline technology and with different values of coupling coefficient. The corresponding simulation results are also presented in this paper together with some discussions. Sections of this paper are organized as following; section II is design procedure of coupled-line couplers. In section III, simulation results are shown and discussed. In section IV, a brief conclusion is presented.

\section{DESIGN PROCEDURE}

The design parameters specification for coupled-line couplers are listed in the tables 1 and 2. These specifications are required to calculate the dimensions 
of the couplers can be. Fig. 3 shows the circuit configuration of the coupled line-coupler that will be designed.

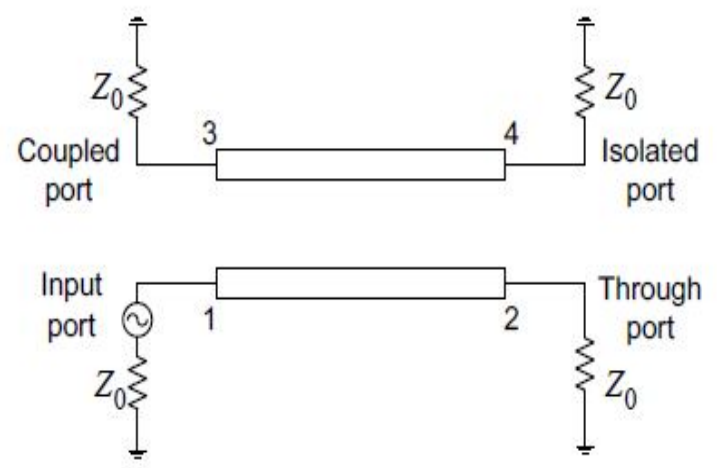

Fig.3. Coupled-line coupler circuit.

Table 1. Coupler-line Coupling coefficient specification

\begin{tabular}{|c|c|}
\hline Coupler & $\begin{array}{c}\text { Coupling coefficient, C } \\
\text { (dB) }\end{array}$ \\
\hline $\begin{array}{c}\text { Coupled-Line } \\
\text { Coupler A }\end{array}$ & 6 \\
\hline $\begin{array}{c}\text { Coupled-Line } \\
\text { Coupler B }\end{array}$ & 10 \\
\hline
\end{tabular}

Table 2. Design parameters specification.

\begin{tabular}{|l|c|}
\hline \multicolumn{1}{|c|}{ Parameter } & $\begin{array}{c}\text { Specificati } \\
\text { on }\end{array}$ \\
\hline Characteristic impedance, Zo $(\Omega)$ & 50 \\
\hline $\begin{array}{l}\text { Centre frequency / center } \\
\text { frequency (GHz) }\end{array}$ & 2.45 \\
\hline Substrate dielectric constant (cr) & 4.5 \\
\hline Substrate thickness, h (mm) & 0.508 \\
\hline Loss tangent (tan $\delta$ ) & 0.0027 \\
\hline $\begin{array}{l}\text { Metallization / copper cladding } \\
\text { (um) }\end{array}$ & 35 \\
\hline Planar technology & Stripline \\
\hline ADS Transmission Line & SCLin \\
\hline
\end{tabular}

\section{A. Coupled-line coupler (A)}

The steps of design are began by calculate the characteristics impedance for both modes. The value of the characteristic impedance for even $\bmod (\mathrm{ZOe})$, and odd mode (Z0o) obtain by using the equations (1) and (2) respectively. It the question, $\mathrm{ZO}$ is characteristic impedance of the transmission line and it is equal to $50 \Omega$, while the value of the coupling coefficient $\mathrm{C}$ is normalized as following:

Coupling factor, $\mathrm{C}=10^{\frac{-6}{20}}=0.5012$

Thus:

$\mathrm{ZOe}=86.74 \mathrm{ohm}$

$\mathrm{ZOo}=28.82 \mathrm{ohm}$
By considering the specification design of the coupled line coupler in table (2) and by using the ADS LineCalc tools, the dimensions of the stripline quarter wave transmission line (SCLIN) are calculated. Table (3) shows calculation dimension results.

Table 3. Coupler-line Coupler A dimension

\begin{tabular}{|c|l|l|}
\hline Coupler & Parameter & Value (mil) \\
\hline \multirow{3}{*}{$\begin{array}{c}\text { Coupled-Line Coupler } \\
\text { A }\end{array}$} & Width (w) & 3.983228 \\
\cline { 2 - 3 } & Length(L) & 568.185039 \\
\cline { 2 - 3 } & Space (S) & 0.919067 \\
\hline
\end{tabular}

The equivalent simulated circuit schematic and layout of coupled-line coupler A that obtained by using ADS software are shown in fig. 4 and fig. 5.

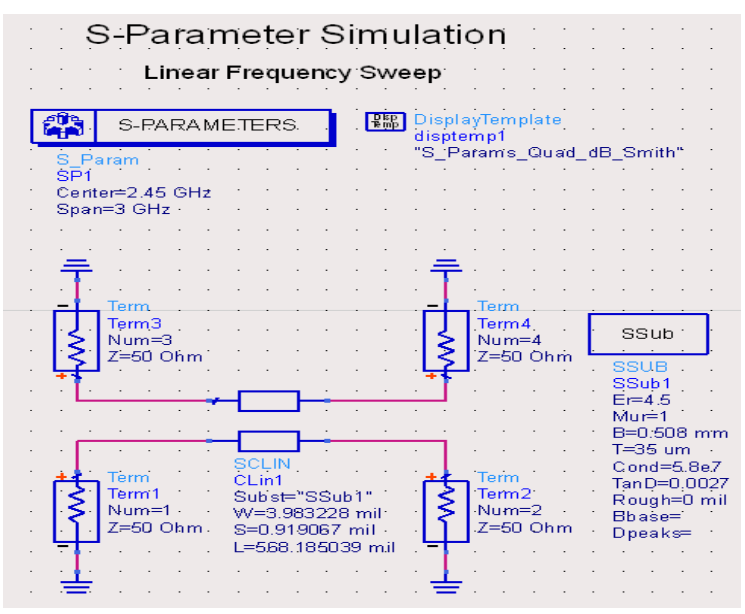

Fig. 4. Circuit schematic of coupled-line coupler A

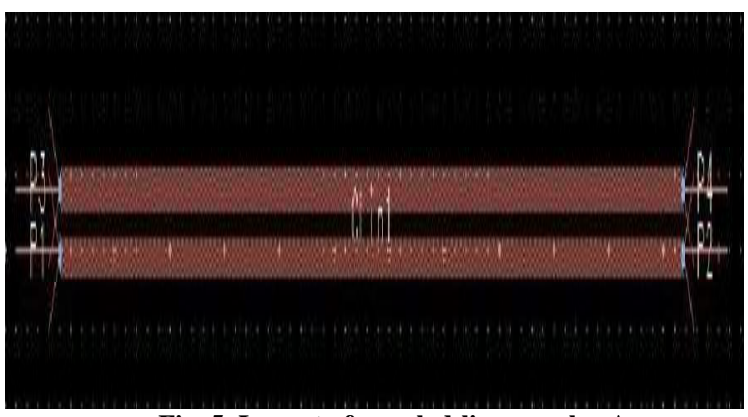

Fig. 5. Layout of coupled-line coupler A

\section{B. Coupled-Line Coupler (B)}

For coupled-line couple B, the same design steps are followed in which firstly calculation of the even mode characteristic impedance ( $\mathrm{ZOe}$ ) and the odd mode characteristic impedance (Z0o) using the equation (1) and (2), but this coupler has $10 \mathrm{~dB}$ coupling coefficient, Therefore:

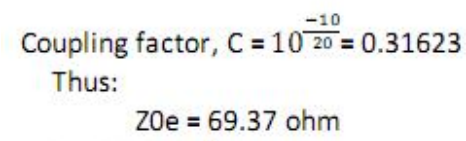

By considering the specification design of the coupled line coupler in table (2) and by using the ADS 
LineCalc tools, the dimensions of the stripline quarter wave transmission line (SCLIN) are calculated. Table (4) shows calculation dimension results.

Table 4. Coupler-line Coupler B dimension

\begin{tabular}{|c|l|l|}
\hline \multicolumn{1}{|c|}{ Coupler } & Parameter & Value (mil) \\
\hline \multirow{3}{*}{ Coupled-Line Coupler A } & Width (w) & 5.430197 \\
\cline { 2 - 3 } & Length (L) & 568.185039 \\
\cline { 2 - 3 } & Space (S) & 2.848760 \\
\hline
\end{tabular}

The layout and equivalent simulated circuit schematic of coupled-line coupler B that obtained by using ADS software are shown in fig. 6 and fig. 7.

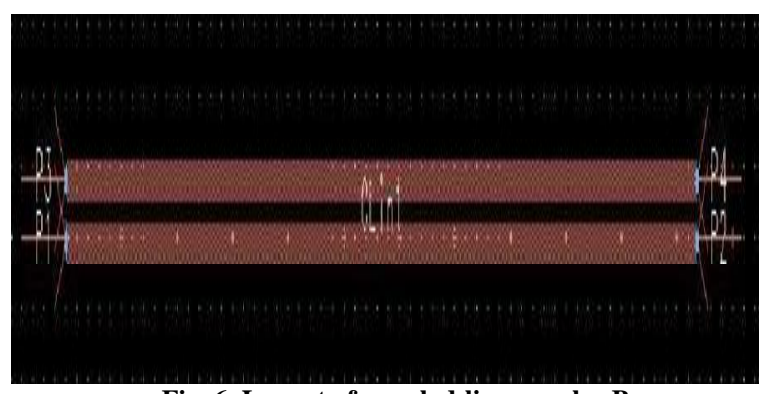

Fig. 6. Layout of coupled-line coupler B.

\section{S-Parameter Simulation Linear Frequency Sweep}
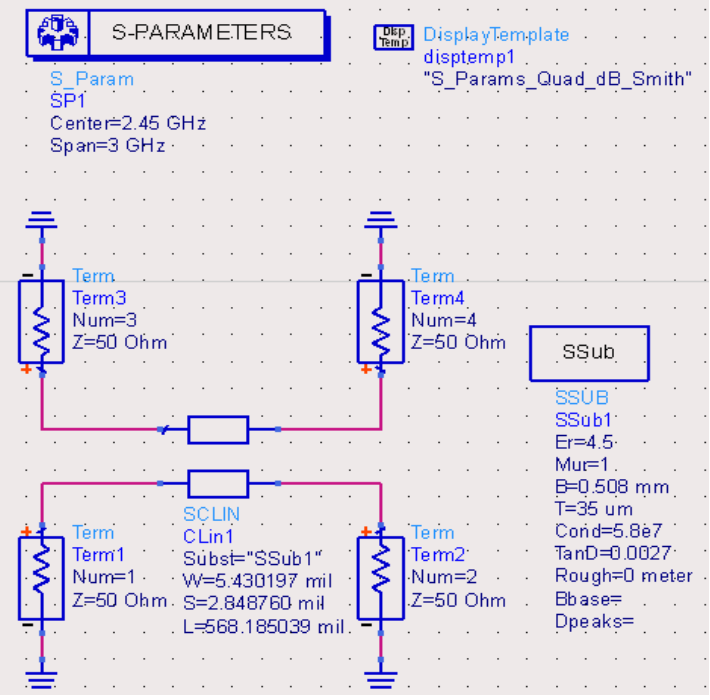

Fig. 7. Circuit schematic of coupled-line coupler B.

\section{SIMULATION RESULTS}

The simulation obtained results are mainly indicated to the $S$ parameters of the coupled -line coupler circuit that have been plotted as shown in fig. 4 and 7 .Both of circuits are four ports network. However, the values of scattering parameters of the ports are obtained from reflection coefficient graphs. Fig. 8 shows the simulation results of the power output at the four ports (in $\mathrm{S}$ parameters) versus frequency for coupled-line coupler A, while fig. 9 illustrates the simulation results for coupled-line coupler B.

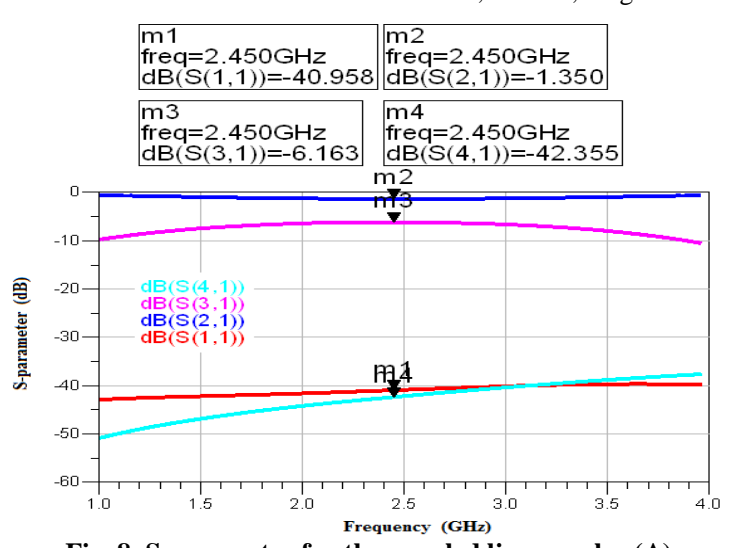

Fig. 8. S-parameter for the coupled line coupler (A)

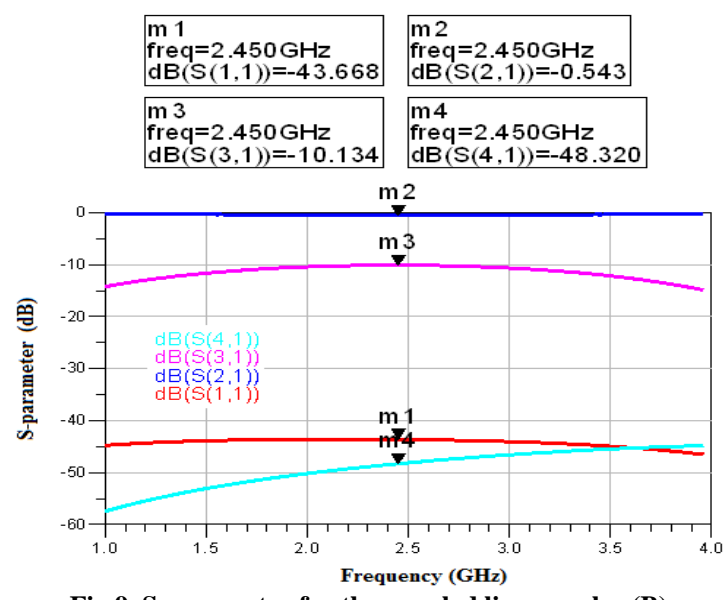

Fig.9. S-parameter for the coupled line coupler (B)

\section{RESULTS DISCUSSION AND COMPARSION}

By analyzing the simulated results, it can be observed that changing the coupling coefficient has an effect on the output power at ports at central frequency $(2.45 \mathrm{GHz})$. Moreover, the dimension of the coupler is also change as the coupled coefficient change. However, table 5 is contain comparison between both coupled-line couples

Table 5. Simulation results comparison

\begin{tabular}{|l|l|c|c|}
\hline \multicolumn{2}{|l|}{$\begin{array}{l}\text { Coupling } \\
\text { Coefficient }\end{array}$} & Circuit A & Circuit B \\
\hline \multirow{4}{*}{$\begin{array}{c}\text { Dimension } \\
\text { ( mil) }\end{array}$} & $\begin{array}{l}\text { Width } \\
(\mathrm{W})\end{array}$ & 3.983228 & 10 \\
\cline { 2 - 4 } & $\begin{array}{l}\text { Length } \\
(\mathrm{L})\end{array}$ & 568.185039 & 568.185039 \\
\cline { 2 - 4 } & $\begin{array}{l}\text { Space } \\
(\mathrm{S})\end{array}$ & 0.919067 & 2.848760 \\
\hline \multirow{4}{*}[\mathrm{S}]{} & $S_{11}(\mathrm{~dB})$ & -40.958 & -43.668 \\
\cline { 2 - 4 } & $S_{21}(\mathrm{~dB})$ & -1.350 & -0.543 \\
\cline { 2 - 4 } & $S_{31}(\mathrm{~dB})$ & -6.136 & -10.134 \\
\cline { 2 - 4 } & $S_{41}(\mathrm{~dB})$ & -42.355 & -48.320 \\
\hline
\end{tabular}


Form the table 5, it can be indicated that the advantage of circuit B in which it denotes coupled-line coupler B, it has low reflection at port 1 and better isolation at port 4. On the other hand, Circuit A that refers to coupled-line coupler A, has small width and space compare to circuit $\mathrm{B}$. The reflection at port 1 is a little greater than that of Circuit B but still fairly good. Therefore, the coupling coefficient is direct proportional to the space between the coupled transmission line and its width.

\section{CONCLUSION}

In this paper, two coupled-line couplers have designed and simulated using ADS 2012.08 software. The designs were for specified given parameters using stripline technology. However, the simulation results of two different values of coupling efficiency were obtained are shown that coupling coefficient is direct proportional to the space between the coupled transmission line and its width. Therefore the coupler are good matching and isolation performance.

\section{REFERENCES}

[1] David M. Pozar, "Microwave Engineering", fourth edition, John Wiley \& Sons. Inc, 1998.

[2] Leo G. Maloratsky, "Passive RF Microwave Integrated Circuits". Elsevier Inc, 2004.

[3] K. H. Yusof, N. Seman and M. H. Jamaluddin " Design and Analysis of Wideband 3 and $6 \mathrm{~dB}$ Coupled-Line Coupler with different Grounding Techniques " 2013 IEEE International RF and Microwave Conference (RFM 2013) December 09-11 ,2013 -Penang Malaysia.

[4] L. Chui, Q. Xue, "Investigation of a Wideband 900 Hybrid Coupler With an Arbitrary Coupling Level," IEEE Trans. Microwave Theory \& Tech., vol. 58, no. 4, pp. 1022 - 1029, April. 2010.

[5] R. Mongia, I. Bahl, and P. Bhartia, RF and Microwave Coupled-Line Circuits. Boston, MA: Artech House, 1999, pp. $1-21$.

[6] Yongle Wu, Weinong Sun, Sai-Wing Leung, Yinliang Diao, Kwok-Hung Chan, and Yun-Ming Siu, Single-Layer Microstrip High-Directivity Coupled-Line Coupler With Tight Coupling" IEEE Transactions On Microwave Theory And Techniques, Vol. 61, No. 2, February 2013. 